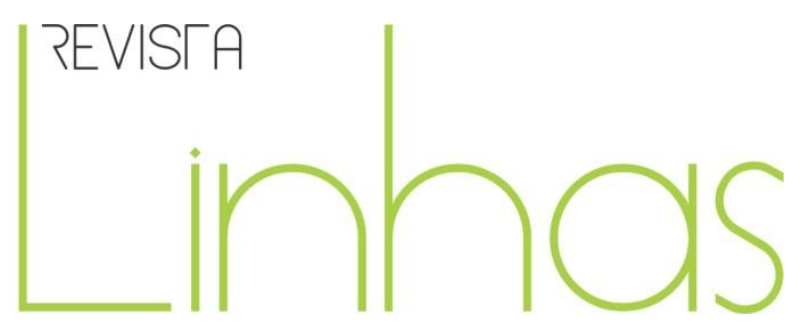

\title{
A Babel do Tempo: Regimes de Historicidade e a história ensinada no universo virtual ${ }^{1}$
}

\begin{abstract}
Resumo
Este artigo pretende discutir a produção didática da história em sites educacionais; nesse sentido, é uma reflexão sobre um tipo de história pública e sua influência na distribuição de conteúdos históricos em nossos dias. Ao mergulharmos nessas páginas, devemos nos preparar para lidarmos como muitas "brechas" no tempo, conforme menciona Hartog. Pode-se dizer que nos deparamos com diferentes regimes de historicidade que se intercruzam a partir do olhar de quem elabora os conteúdos. Assim, a intenção é investigar formas de pensamentos históricos e quebras de sentido que, muitas vezes, tornam esses espaços verdadeiras bricolagens conceituais.
\end{abstract}

Palavras-chave: Regimes de Historicidade. Internet. História Pública.

\author{
Sônia Meneses \\ Universidade Regional do Cariri - \\ URCA - Brasil \\ sonia.meneses@gmail.com \\ Egberto Melo \\ Universidade Regional do Cariri - \\ URCA - Brasil \\ egbertomelo13@yahoo.com.br
}

\begin{abstract}
Para citar este artigo:
MENESES, Sônia; MELO, Egberto. A Babel do Tempo: Regimes de Historicidade e a história ensinada no universo virtual. Revista Linhas. Florianópolis, v. 18, n. 37, p. 154-178, maio/ago. 2017.
\end{abstract}

\section{DOI: $10.5965 / 1984723818372017154$}

http://dx.doi.org/10.5965/1984723818372017154

\footnotetext{
${ }^{1}$ Este artigo é parte de uma pesquisa em andamento financiada pelo CNPQ no projeto: Internet, Escrita da História e Ensino: Sites educacionais e os desafios ao ensino de história e desenvolvida no grupo de Pesquisas em Ensino de História e Cidadania NUPHISC, da Universidade Regional do Cariri-URCA. Bolsista da pesquisa a graduanda Ana Júlia Gomes de Oliveira.
} 


\title{
The Babel of Time: Regimes of Historicity and history taught in the virtual universe
}

\begin{abstract}
This article discusses the didactic production of history in internet educational pages. The intent is a reflection on a type of Public History and on its influence on the distribution of historical contents in our days. As we submerge ourselves in these pages, we should prepare to deal with many "loopholes" in time, as mentioned by Hartog. It may be said that we encounter different "regimes of historicity", which intersect themselves from the perspective of the one who elaborates the contents. The intention is therefore to investigate forms of historical thoughts and meaning breaches that often turn these spaces into true conceptual bricolages.
\end{abstract}

Keywords: Regimes of Historicity. Internet. Public History. 
Dessas premissas incontrovertíveis deduziu que a Biblioteca é total e que suas prateleiras registram todas as possíveis combinações dos vinte e tantos símbolos ortográficos (número, ainda que vastíssimo, não infinito), ou seja, tudo o que é dado expressar: em todos os idiomas.

Tudo: a história minuciosa do futuro, as autobiografias dos arcanjos, o catálogo fiel da Biblioteca, milhares e milhares de catálogos falsos, a demonstração da falácia desses catálogos, a demonstração da falácia do catálogo verdadeiro, o evangelho gnóstico de Basilides, o comentário desse evangelho, o comentário do comentário desse evangelho, o relato verídico de tua morte, a versão de cada livro em todas as línguas, as interpolações de cada livro em todos os livros; o tratado que Beda pôde escrever (e não escreveu) sobre a mitologia dos saxões, os livros perdidos de Tácito. (A BIBLIOTECA DE BABEL, Jorge Luís Borges, 1999, p. 38)

Em 1944, Jorge Luís Borges imaginou, a partir da literatura, uma misteriosa Biblioteca. Seu número indefinido de galerias hexagonais estava sempre a dar acesso a novas portas para outras galerias infinitas. Nela, bibliotecários desnorteados buscavam encontrar, em meio às ilimitadas possibilidades de volumes de livros, um livro, "talvez o catálogo dos catálogos", que pudesse decifrar o sentido da existência ou, quem sabe, da própria Biblioteca. Mais de sessenta anos depois, desenhou-se na sociedade contemporânea um espaço, cujas galerias hexagonais podem ser acessadas através dos hiperlinks de um universo virtual; pode-se dizer que mergulhamos na Biblioteca de Babel borgeana ao ligarmos o computador. Assim, deparamo-nos com o grande desafio de construir sentido em meio à ilimitabilidade de conhecimentos e bens culturais disponíveis a cada um que se aventura por essa biblioteca infinita.

A expansão da Internet na primeira década do século XXI produziu uma mudança significativa nas relações sociais, sobretudo quando pensamos no acesso de milhões de usuários sobre a produção de conteúdos em diversos formatos e linguagens no universo virtual. Tais mudanças avançaram velozmente para vários campos do conhecimento que, atualmente, se veem desafiados a uma reordenação de seus objetos, problemas e temáticas. A partir do ciberespaço, novas qualidades cognitivas são agenciadas, posto que se colocou como imperativa a necessidade de construção de distintas formas de aprendizado e produção de conhecimento. 
Além de novos suportes para a leitura, encontramos um novo leitor que já nasce imerso em uma estrutura de pensamento pautada pelo acesso ilimitado de conteúdos e informações na rede mundial de computadores. Sujeitos que conseguem operar com uma pluralidade de saberes que se cruzam de forma, por vezes, desconexas gerando processos de apropriação até aqui inéditos. Um momento, cujos neologismos relacionados ao ambiente virtual, fazem parte da vida e de nossas ações do dia a dia. Somos usuários "conectados", "linkados", "blogueiros", twiteiros de uma cibercultura que interliga não apenas pessoas, mas saberes e identidades que estão além de todas as fronteiras territoriais.

Todavia, é preciso considerar que nem todos os países e povos têm acesso igual à tecnologia. Mesmo quando o acesso é relativamente universalizado, como é o caso do Brasil, um dos países que mais cresceu em conexão nos últimos anos, essa assimilação ainda é confusa, intercambiante e cheia de lacunas.

Estabelecer as diferenças entre produtores e consumidores nesse universo virtual é um desafio ao conhecimento e ao ensino, especialmente, porque delimitar espaços e autores em um universo que, aparentemente, é caótico e de todos, parece se constituir como um dos problemas sérios a serem enfrentados.

Para termos uma ideia do poder dessa ferramenta, no ano de 2014, o Brasil ocupou O $4^{\circ}$ lugar em acesso à Internet no mundo, perfazendo um total de 107,7 milhões de internautas. Uma cifra surpreendente quando consideramos o número de estudantes na rede pública de ensino no Brasil, que era de pouco mais de 41 milhões naquele ano².

Porém, há ainda muitos brasileiros sem Internet, segundo "pesquisa Nacional por Amostra de Domicílios (PNAD), do IBGE, 24,2 milhões de lares de renda de até 2 salários mínimos (em torno de $\mathrm{R} \$ 1,4$ mil) não estão conectados à Internet. O mesmo vale para 7,5 milhões de lares na área rural do país" (BBC-Brasil, 24 de novembro de 2014). Mas o número de conectados vem crescendo rapidamente e nos dados atualizados de 2015, também pela PNAD, houve um crescimento de $11,4 \%$ sobre o percentual de 2014 . A pesquisa

\footnotetext{
${ }^{2}$ Dados do Ministério da Educação, Censo Escolar. Disponível em: <http://portal.inep.gov.br/basica-censo>. Acesso em: 16/02/2015.
} 
constata que hoje, $54,4 \%{ }^{3}$ dos brasileiros são internautas assíduos, ou seja, mesmo que não tenham computadores conectados à Internet em casa, acessam por meios como cybers, celulares, etc. Dados similares apontam que os internautas da América Latina são os que mais tempo ficam conectados à Internet:

Más allá de transacciones online, las investigaciones están indicando fuerte uso del internet por latinoamericanos: Los argentinos pasan un promedio de 5 horas con 11 minutos al día en internet, Los brasileños pasan un promedio de 6 horas con 3 minutos al día en internet. (HAY más de 330 millones..., 2016)

Tais números nos demonstram a importância que este espaço de informação assumiu no cotidiano de leitores nas mais variadas faixas etárias. Por outro lado, chamam-nos atenção para o fato de que nenhuma reflexão que pretenda se realizar sobre processos de leitura, apropriação e produção do conhecimento no tempo presente possa ser feita sem considerar o universo virtual. Estamos vivendo uma verdadeira revolução cultural em virtude do acesso à Internet e seus produtos, aspecto que acentua ainda mais o poderoso processo de globalização já em curso, como afirma Canclini (2013, p. 13) "as maiores fontes de assombro, agora, provêm da diversidade do mundo presente na própria sociedade daquilo que está distante ou é ignorado e que a conectividade aproxima".

A partir dessa constatação, evidencia-se o papel da Internet como recurso de tradução, leitura e produção de novos sentidos na contemporaneidade. Aspecto que acabou por atingir também os registros sobre o passado, na medida em que os chamados acontecimentos emblemáticos são fortes referentes de disputas, debates e discursos no mundo virtual.

Desta forma, existem vários aspectos a serem considerados nesse processo, uma vez que são muitas dimensões possíveis relacionadas tanto à produção de fontes primárias para a pesquisa histórica, como a formulação de conteúdos de caráter histórico vinculados na rede mundial de computadores. Neste artigo, a preocupação será pensar especificamente sobre a narrativa histórica reproduzida no universo virtual. Interessa-nos compreender, por exemplo: ideias de história, tempo e regimes de historicidades

3 Segundo a pesquisa, a população brasileira é de 200,5 milhões de habitantes: <http://www.ibge.gov.br/home/mapa_site/mapa_site.php\#populacao>. 
presentes nessas narrativas. Coloca-se a provocação de refletir algumas questões epistemológicas relacionadas a essa produção histórica, ao mesmo tempo em que, questionamos os problemas práticos dessa, uma vez que as páginas são espaços fundamentais para o ensino de história, acessadas não apenas por alunos, mas também por professores.

\section{Como pensar o ensino de história no ciberespaço?}

Milhões de páginas se multiplicam na Web, dedicadas a temas relacionados ao ensino. Isto representa uma mudança significativa na apropriação dos conteúdos por parte dos educandos e professores em diversas modalidades e campos disciplinares. Falase, assim, da adequação de conteúdos e da formulação de outros impulsionados pelas demandas desse espaço. Deste modo, pensar especificamente o uso de sites educacionais é uma tarefa que pode nos indicar a elaboração de novos saberes em nosso tempo. No caso da história, há uma espantosa produção virtual cujo conteúdo é impossível dimensionar na sua totalidade, são muitos “fazedores de história”, posto que:

A história se tornou um produto cobiçado, não somente de legitimação, mas mercadoria simbólica vendida em bancas de jornal (...). Nesse sentido, é fundamental problematizamos uma questão premente em nossa época: o conhecimento histórico elaborado por não historiadores de ofício. (MENESES, 2007, p. 05)

Questionar sobre a escrita didática da história se coaduna com a necessidade de investigarmos as dimensões públicas de história, nesse caso, efetivadas no universo virtual. Referimo-nos, especialmente, a uma produção que se realiza para além das regras do mundo acadêmico, mas que, ao mesmo tempo, também lida com formulações advindas dele. A preocupação não é apenas compreender que tipos de narrativas são produzidas nesses espaços, mas sobretudo, interrogar como elas operam com demandas públicas do ensino, ou seja, como a história funciona nessa sociedade, já nos propunha pensar Michel de Certeau (2002). 
Ao lidarmos com esses materiais, um dos primeiros problemas a serem enfrentados diz respeito à impossibilidade de um mapeamento completo dos produtos que tratam de um dado tema, algo muito semelhante à metáfora de Jorge Luís Borges em sua "Biblioteca de Babel”, cujas dimensões infinitas levavam a uma busca incessante pelo conhecimento inesgotável.

Nessa empreitada, definiu-se uma metodologia ${ }^{4}$ de trabalho a fim de recortar nosso universo de pesquisa. Muitos aspectos nesse trabalho ainda são experimentais e os resultados de incursões que vêm sendo feitas nos últimos anos são exemplos de como podemos tornar narrativas dispersas em objeto do conhecimento válido 5 .

Para escolher os sites, optamos por selecioná-los, inicialmente, de acordo com o motor de busca do site Google Brasil ${ }^{6}$, maior buscador da rede e que, no Brasil, tem a predominância entre usuários e empresas. Estima-se que mais $94 \%$ das buscas na Internet no Brasil sejam feitas através desse site, assim, a partir de alguns termos de busca ${ }^{7}$ como: “História”, “Historiografia”, “História do Brasil”, começamos a selecionar nossos objetos $^{8}$. O sistema de buscas do Google opera com vários algoritmos sendo que o mais conhecido deles é o PageRanke que ordena as páginas numa classificação dos links mais acessados pelos usuários; desta forma, a lógica é: quanto mais se acessa, mais se acessa?

\footnotetext{
${ }^{4}$ Quando estávamos em processo de finalização desse texto, nos deparamos com um trabalho metodológico parecido realizado pela professora Nucia Alexandra Nunes de Oliveira em artigo publicado na revista Tempo \& Argumento, intitulado: História e Internet: Conexões Possíveis. Revista Tempo e Argumento, Florianópolis, v. 6, n. 12, p. 23-53, mai./ago. 2014. Embora o artigo da professora aborde temas parecidos, aqui desenvolvemos uma metodologia diferente para a escolha do nosso material que une aspectos quantitativos e qualitativos como exposto no texto. Além disso, lidaremos com questões epistemológicas dessa produção tendo como elemento central pensar o alcance do conceito de Regime de Historicidade de Hartog e Koselleck a partir dessa produção.

${ }^{5}$ Destaco aqui os novos trabalhos de historiadores que se propõem a pensar uma história digital. No Brasil, os trabalhos de Anita Luchessi são bastante promissores.

${ }^{6}$ A Serasa Experian divulgou uma pesquisa que revelou os buscadores mais utilizados no Brasil em dezembro de que ano? O Google Brasil lidera o ranking com 94,3\% de participação, seguido pelo Google.com com $2 \%$. Em terceiro lugar, aparece o Bing, com 1,7\%. Os dados foram obtidos com base na Hitwise, ferramenta de inteligência digital da empresa. Disponível em: http://olhardigital.uol.com.br/noticia/rankingdos-buscadores-no-brasil/46539. Acesso em: 30 de agosto de 2016.

${ }^{7}$ A busca foi realizada através do site: <www.google.com.br>. O Google mantêm sites específicos nos países onde atua, isso significa que já há uma pré-seleção na busca, uma vez que ele direciona prioritariamente para a navegação em páginas do próprio país de origem. Isso não impede o acesso a outros países, mas na busca comum, o acesso é prioritariamente vinculado ao país da busca.

8197 milhões de ocorrências para o termo "história" e, quando se especifica o termo para "história do Brasil”, obtém-se o número de 14 milhões e novecentas mil ocorrências.

${ }^{9}$ Sobre o algoritmo de busca do Google, há várias controvérsias e polêmicas, especialmente aquelas que
} 
A partir daí, passamos a trabalhar com as páginas sugeridas nas primeiras opções. Embora tal configuração não seja precisa, nos possibilitou um ponto de partida numa seleção viável dos sites a serem trabalhados. Após a seleção quantitativa, passamos a uma investigação qualitativa das páginas tendo por base a análise de elementos predefinidos como: longevidade, regularidade de publicações, dados estatísticos de acesso (presentes em alguns), diversidade temática, iconografia e páginas em redes sociais, o que nos permitiu ter indícios sobre seus usuários. Esses elementos complementam o processo de busca de forma a termos uma seleção qualitativa do nosso material.

Chegamos a um número de 15 sites que demonstravam grande potencial, mesmo assim, ainda muito numeroso para lidarmos, uma vez que nos deparamos com centenas de textos em cada um deles. Após o trabalho mais refinado, optamos por cinco páginas que reuniam o maior número de características destacadas acima. São eles: Historianet.com.br, InfoEscola.com, HistóriadoBrasil.net, SoHistoria.com.br e o Brasilescola.com.br.

Dos sites pesquisados, o Historianet (http://www.historianet.com.br/home/) está há mais tempo em exercício na rede, desde 1999. Assim, é o que mais atende ao critério de longevidade. Seu organizador principal é o professor Claudio Barbosa Recco, que é licenciado em história, foi professor da rede pública estadual de São Paulo e atua na rede particular de ensino e de pré-vestibular desde 1987. Conta ainda, com a colaboração dos professores Cristiano Rodrigo Catarin, licenciado em História e professor da rede pública estadual de São Paulo e Gabriel Luiz Bandouk, que também licenciado em história, lecionou na rede pública estadual de São Paulo desde 1985 e atua em cursos de prévestibular. O site contém textos de diversos autores, entre eles professores, acadêmicos e, em alguns casos, jornalistas. Além disso, algumas vezes há reprodução de textos de livros didáticos ou revistas. O site também é parceiro do Portal IG.

O site InfoEscola - Navegando e Aprendendo (http://www.infoescola.com/) também é hospedado no IG (Internet Group), um dos maiores provedores de acesso brasileiro,

\footnotetext{
dizem respeito à manipulação das buscas a fim de favorecer empresas patrocinadoras e grupos governamentais; assim, não há uma precisão absoluta nessas listas. Muitos dos primeiros sites podem ser parceiros comerciais, por isso esse não pode ser o único elemento de seleção.
} 
mas tem autonomia jurídica sendo organizado e mantido pela empresa InfoEscola Serviços em Informática Ltda., estando sua equipe situada no estado de Santa Catariana. A página está há 10 anos em funcionamento, iniciando suas atividades em 2006. Trata-se de um site que reúne uma grande variedade de temas voltados para o ensino, sendo seu índice dividido tanto em disciplinas, como por assuntos.

O site História do Brasil (http://www.historiadobrasil.net/) funciona desde 2005, os textos são de autoria de Jefferson Ramos, segundo informação obtida via e-mail, proprietário e único editor do site. Ramos é formado em História (bacharelado e licenciatura) e utiliza como fontes livros didáticos de História do Ensino Fundamental e Médio. Ainda segundo o autor, através de e-mails que recebe de usuários, o perfil de seus leitores é de maioria composta por estudantes do ensino fundamental e médio (entre $12 \mathrm{e}$ 18 anos), assim, "a linguagem (didática) e estrutura dos textos são focadas nas necessidades de pesquisa destes alunos. Há também uma parcela significativa de visitantes, que são adultos interessados por História do Brasil."”10

O Só História (http://www.sohistoria.com.br/index2.php) faz parte do grupo Educacional Virtuous (http://www.grupovirtuous.com.br/) que, de acordo informação do próprio site, desenvolve sites e portais educacionais abertos e gratuitos, e também oferece venda de produtos na área de educação. O Grupo Virtuous mantém vários sites voltados para disciplinas, dentre eles o "Só História". Segundo descrição do grupo, o Só História, criado em 2009, surgiu “para preencher uma lacuna no ensino de História na Web" (GRUPO VIRTUOUS, acesso em 19/09/2016).

Por último, o Brasil Escola (http://brasilescola.uol.com.br/) é um grande portal educacional ligado ao portal UOL que, por sua vez, pertence ao Grupo Folha, um dos maiores produtores de informações do mundo. O Brasil Escola é o mais complexo dos cinco e é dividido em várias seções: Disciplinas, Enem, Educador, Monografias, etc. Produzido pela Rede Omnia (http://www.redeomnia.com/), fundada no ano de 2000, em Goiânia, é dedicada aos produtos educacionais. Na definição do site, "é a empresa proprietária dos maiores sites de educação do país" (REDE OMNIA, acesso em 19/09/2016). Em sua página na rede social mais acessada do país, o Facebook, o Brasil Escola tem o maior número de seguidores, mais de 2 milhões e 100 mil usuários.

\footnotetext{
${ }^{10}$ Essas informações foram obtidas com o autor através de entrevista por e-mail.
} 
As configurações estruturais dos sites pesquisados, inclusive dos que não serão objeto direto nesta análise, são parecidas, com algumas exceções. A partir de um menu de entrada, é possível acessar o conteúdo em uma divisão clássica da história - Geral e do Brasil. A maioria dos sites obedece à periodização tradicional da história: História Geral com as subdivisões: Antiguidade - História Medieval - História Moderna - História Contemporânea. No caso do site InfoEscola, aparecem mais seis subdivisões além dessas, são elas: História da África, História da América Espanhola, História da Ásia, História da Europa, História da Oceania e História do Oriente Médio. Todavia, alguns dos conteúdos relacionados a esses temas são bastante incipientes, a exemplo da História da África que conta com apenas um artigo, intitulado: "Invasão italiana da Etiópia”" . O Historianet traz ainda um tópico sobre "atualidades", que diz respeito a uma História do Tempo presente numa compreensão clássica sobre os acontecimentos históricos. O Brasil Escola é o único que opera com uma configuração diferente tanto de periodização, como de conteúdo, optando por uma história temática, à qual voltaremos depois. Nos quatro primeiros sites a divisão da história do Brasil segue o mesmo padrão: Brasil Colônia - Brasil Imperial/Monarquia - Brasil República.

Como nos chama atenção Melo (2014), esse modelo de compartimentação se situa no próprio processo de constituição da disciplina de história no Brasil no século XIX, cujas influências francesas foram incontestes. Desta forma, o autor destaca que o currículo francês foi pensado em meios aos debates desencadeados na Revolução Francesa em 1789, reforçando o modelo linear da história e que tinha a França como o modelo da civilização do progresso, portanto, “em 1865, o currículo francês assumiu uma estrutura que influenciaria diretamente os currículos brasileiros (...) o sistema quadripartite até hoje presente nos currículos ocidentais, inclusive nas Universidades, a exemplo do que ocorre no Brasil” (MELO, 2014, p. 105). Sob essa influência, a história do Brasil também foi ordenada no formato tripartite e linear.

Flávia Caimi (2009) destaca que, durante o século XX, a história ensinada passou por três fases quanto à organização curricular; a primeira delas diz respeito exatamente a essa história seriada convencional. A partir de 1942, com a reforma de Gustavo de

\footnotetext{
${ }^{11}<$ http://www.infoescola.com/historia-da-africa/>.
} 
Capanema, a história do Brasil se coloca como disciplina autônoma que teria a função de organizar os acontecimentos marcantes, biografias, etc.

Têm-se, a partir de então, as bases para a composição do chamado "currículo seriado da história", também conhecido como "história convencional", pelo qual se estudava, primeiramente, história do Brasil ( $5^{\mathrm{a}}$ e $6^{\mathrm{a}}$ séries), em sua organização tripartite (história colonial, imperial e republicana) e, depois, quando os alunos já estivessem mais maduros, na $7^{\mathrm{a}}$ e $8^{\mathrm{a}}$ séries, a história geral, com sua organização quadripartite (antiga, medieval, moderna e contemporânea). (CAIMI, 2009, p. 3)

A descrição acima nos chama atenção para o fato de que boa parte dos sites pesquisados se mantêm fiel a essa proposição curricular. Uma configuração que tem por base a ideia de uma história universal, aspecto agregador da narrativa histórica que se aprofunda com o desejo de estabelecer, no século XIX, o caráter científico e disciplinar da história. Importante destacar ainda a formação das nacionalidades no século XIX como fator marcante em vários projetos da disciplina histórica que deveria servir para a construção e solidificação de símbolos nacionais. Por exemplo, na subdivisão "Brasil Republicano" de alguns sites, acessamos uma extensa lista de temas gerais que têm ênfase na dimensão política, é o caso do Historianet ${ }^{12}$ e do InfoEscola ${ }^{13}$.

O site Historianet apresenta 53 artigos dedicados à República e destes, apenas três trazem um enfoque mais direto em questões sociais ou culturais ${ }^{14}$; outros apresentam biografias de alguns personagens do período, como é o caso de Lampião, Pe. Cícero, Lino Guedes, Francisco Julião, Celso Furtado, dentre outros.

O site InfoEscola divide o tópico "Brasil Republicano" em três subcategorias: Ditadura Militar, Era Vargas e Mandatos Presidenciais do Brasil. São $61 \operatorname{artigos}^{15}$ nas três subcategorias em que se mantém a abordagem política dos eventos. Todos os textos se concentram nas narrativas de acontecimentos relacionados a governos presidenciais, revoltas, movimentos sociais, etc.

\footnotetext{
${ }^{12}$ Ver: <http://www.historianet.com.br/conteudo/default.aspx?categoria=24>.

${ }^{13}$ Ver: <http://www.infoescola.com/brasil-republicano/>.

${ }^{14}$ São eles: "A igreja e as questões sociais"; “As revoltas urbanas na República”; "O Teatro na época da ditadura”.

${ }^{15}$ Ver: <http://www.infoescola.com/brasil-republicano/>.
} 
No caso do História do Brasil ${ }^{16}$, os problemas são ainda maiores. São oferecidas sínteses bastante resumidas dos acontecimentos cujo formato quase sempre repete uma sistematização dividida em tópicos: “O que foi?”, “Causas”, “Início e Fim”, “Conclusão”. Os artigos são dispostos aleatoriamente e não há um esclarecimento sobre o que orienta a organização para o leitor. Também temos uma média de 50 artigos sobre a República e tal como os demais, a história política tradicional figura como elemento preponderante: governos presidenciais, revoltas, personagens e rebeliões. Acrescentam-se artigos dedicados exclusivamente à apresentação de cronologias, a exemplo de "Cronologia do Brasil República - principais fatos e datas - Cronologia do Brasil República, fatos históricos, datas importantes".

Boa parte dos sites apresenta uma escrita marcada pela ideia de progresso e aceleração cuja dimensão teleológica, racional e política assinalava aquilo que Hartog denominou de "moderno regime de historicidade", ou seja, naquela perspectiva a história era escrita tomando por base o ponto de vista do futuro e a história nacional se tornou o tema predileto dessa narrativa (HARTOG, 2013). Destaca-se aqui que tal escolha não é exatamente uma opção deliberada pelo moderno regime de historicidade, conforme define Hartog, mas que os autores dessas páginas ainda orientam seu olhar influenciados por elementos característicos desse modelo o que, muito provavelmente, reflete um processo de formação desses profissionais tanto em nível acadêmico, como social.

De forma geral, a história serial predomina como núcleo organizador dos conteúdos e, mesmo em alguns sites que tentam dedicar uma seção à história temática, como é o caso do Historianet, ela é feita desvinculada do restante do programa, como um elemento a parte. Na seção temática do HistoriaNet, encontramos temas variados, desde aqueles de interesses muito específicos do campo da historiografia, como o artigo sobre Edward Said" até temas como "A música na Mesopotâmia" e os significados das cores das bandeiras. Aspectos que acabam por realizar uma abordagem um tanto estereotipada da história temática como espaço para satisfazer curiosidades.

\footnotetext{
${ }^{16}$ Ver: <http://www.historiadobrasil.net/brasil_republicano/>.

${ }^{17}$ Contribuições de Edward Said. Ver: <http://www.historianet.com.br/conteudo/default.aspx?codigo=932>.
} 
Mas é preciso destacar que nem todos se organizam dessa maneira quando dizem fazer uma história temática, a exemplo do Brasil Escola, no qual os conteúdos se articulam numa estruturação teórico-metodológica bastante clara como será demostrado a seguir.

A história factual de caráter historicizante e pouco crítica que algumas das páginas apresentam, foi insistentemente questionada ao longo das últimas décadas, especialmente nos debates sobre ensino por historiadores como Marcos Silva (1986), Katia Abud (1986), Circe Bitencourt (1998), Selva Guimarães Fonseca (1996), Elza Nadai (1988), dentre outros. Uma das reflexões mais comuns diz respeito ao fato desse ensino levar a uma cristalização de acontecimentos emblemáticos da história do Brasil, assim como, uma cultura histórica que pretendia construir uma memória oficial homogeneizante baseada em personagens exemplares e na personificação da história.

Esse modelo, sem dúvida, teve e ainda tem um papel muito significativo no ensino em nosso país, e as opções curriculares de boa parte desses sites nos demonstram isso. Todavia, essa produção também pode ser vista como uma grande trama na qual se cruzam diferentes tessituras temporais e ideias de história. Se ao primeiro contato nos saltam aos olhos as escolhas de uma narrativa tradicional, elas escondem muito mais elementos do que revelam na superfície. Falamos de regimes de escrita e de história que são capazes de operar em diferentes ritmos de significação através desses textos. É o que veremos a seguir.

\section{Regimes de historicidade na escrita didática da história}

Esses cortes, vamos chamá-los ainda de brechas no tempo, retomando o diagnóstico feito por Hannah Arendt, isto é, esses intervalos totalmente determinados pelas coisas que não são mais e pelas coisas que não são ainda. Brechas, pois há uma pausa e esse tempo parece desorientado. (HARTOG, 2013, p. 139)

Ao navegarmos nas páginas, devemos nos preparar para lidarmos com muitas dessas "brechas" no tempo mencionadas por Hartog. Pode-se dizer que em um mesmo 
site nos deparamos com diferentes regimes de historicidade que se intercruzam a partir do olhar de quem elabora os conteúdos. Assim, se ao primeiro olhar predomina uma perspectiva didática tradicional, isso não significa que não encontraremos fissuras nesse modelo; quebras de sentido que fazem com que muitas vezes haja uma certa confusão de tempos históricos evocados nos sites. Podemos dizer que há hibridizações de paradigmas na organização desses conteúdos, sendo alguns mais complexos do que outros. Misturam-se perspectivas historiográficas distintas que fazem desses espaços verdadeiras bricolagens conceituais bastante difíceis de situar em apenas uma vertente teórica ou mesmo temporal.

Mas como isso se realiza na prática? Como identificar diferentes formas de compreensão históricas presentes nesses espaços? A partir daqui será feita uma análise em alguns textos de caráter teórico presentes nos sites. Optamos por estes por apontarem aspectos de suas escolhas epistemológicas, embora, ressalte-se que, mesmo apresentando uma certa definição de história, ao tratar conteúdos, os sites possam operar outras abordagens.

Vejamos algumas definições de história presentes neles:

Site InfoEscola.

(... ) pode-se deduzir que a História é a soma do estudo dos costumes do passado, com a descrição dos fatos ocorridos, mostrando como era a vida dos povos que vieram antes de nós. Para que isso possa ser feito, é necessário que pessoas especializadas, os historiadores, entrem em cena. Seu trabalho consiste em estudar documentos, registros, vestígios e marcas deixadas pelos povos que viveram no passado.

(MACHADO, 2016 - Grifos dos autores)

Após apresentar a descrição da história a partir de cinco autores, Herder, "a história é o estudo do passado"; Marc Bloch "ciência dos homens no transcurso do tempo"; Febvre "processo de mudança contínua"; Aurélio Buarque de Holanda "narração metódica dos fatos notáveis"; Sérgio Buarque de Holanda “estudo do que os homens do passado fizeram", o autor do texto acima chega à conclusão de que a História é a soma 
de tudo que ocorreu no passado, sejam costumes, acontecimentos, enfim, "a vida dos povos que vieram antes de nós".

Transitam no texto elementos que nos remetem ao modelo de uma escrita que tem como ponto de vista o futuro - "a soma de tudo que ocorreu" - assim, a "história é entendida como processo e tempo como se direcionando a um fim (progressão)" (HARTOG, 2003, p. 11). Nesse sentido, compete aos historiadores a sistematização desse conhecimento; a ele é atribuída a função de mediador através dos rastros deixados por esse passado. A ideia de "soma" nos direciona à compreensão da história como singularidade da humanidade, conhecimento universal que se acumula e que reúne "tudo que ocorreu". Como destaca Hartog (2003, p. 13), citando Droysen, na perspectiva moderna, “além das histórias há a História”, nos diz Hartog:

Na moderna concepção de história, a exemplaridade cede lugar ao unívoco. Algum dia, no futuro, alguém estabelecerá uma lei. Ou, para empregar uma outra formulação típica de fins do século XIX, algum dia no futuro virá o dia glorioso da "synthèse", mas por enquanto "c'est l'ordinaire ingrat de l'analyse”! (HARTOG, 2003, p. 13)

A sugestão de que há no texto a efetivação de uma perspectiva histórica aparentemente superada, demonstra-nos como os regimes de historicidade se configuram como um arcabouço cultural bastante durável para as sociedades. Embora percam a predominância em determinado momento, seus ecos permanecem no tempo.

Assim, suas permanências podem ser lidas como "brechas" no tempo, como destaca Hartog. Ocorrem concomitantemente a outros regimes de história; é uma espécie de enquadramento que organiza o tempo e que o conforma sob uma dada compreensão, ao nos remetermos a Koselleck, é "estrato" do tempo que age simultaneamente a outros.

Vejamos outra definição de história, agora retirada do site Historianet:

Diante das transformações mundiais registradas em ritmos cada vez mais acelerados, diante da renovação das "permanências", dos valores e ações do homem, diante do resgate do tempo e do espaço, a escrita da história depara-se com um novo desafio e uma feliz proposta disposta a abordar 
as mais diversas intervenções do homem ou dos homens em diferentes períodos e circunstâncias, sem privilegiar personagens "ilustres". Existe uma tendência consciente e decidida em problematizar e considerar as relações estabelecidas também no passado das resistências, das manifestações, dos personagens "iletrados" (...) A inovação beneficia-se da história para elaboração do processo de significados e também da estruturação da forma do futuro. Para Hobsbawm a história é dinâmica de tal forma que consegue reunir a capacidade de colaborar com previsões teleológicas. ${ }^{18}$ (, HISTORIANET,2016 - Grifos dos autores)

A exemplo do anterior, vemos novamente aspectos de uma perspectiva moderna no enquadramento do tempo, todavia, o texto mescla questões mais contemporâneas postas ao conhecimento histórico. Ao serem destacados aspectos como permanência, inovação, necessidade de problematização sobre as relações do passado, o texto se mostra atualizado com os debates desencadeados nas últimas décadas do século XX. Porém, podemos perceber como o autor apresenta uma linha muito clara de explicação que tem como base a busca por uma síntese histórica: "uma feliz proposta disposta a abordar as mais diversas intervenções do homem ou dos homens em diferentes períodos e circunstâncias, sem privilegiar personagens 'ilustres"”.

Não por acaso, embora articule um conjunto de definições de história que variam desde a Escola dos Annales, citando Bloch e Febvre, até uma breve apresentação sobre História Cultural a partir do historiador brasileiro Ronaldo Vainfas, é com Hobsbawm que elabora sua compreensão sobre o passado. Citando o texto "O sentido do Passado", do livro Sobre História (2002), conclui: "limitar a história ao conhecimento e deslocamento ao passado não explica a complexidade contida na abordagem das mudanças proferidas pelo homem, ou pelos homens, no tempo ou nos períodos". Dessa forma, a história "está acumulando, com o passar do tempo, maior credibilidade e estrutura metodológica”. Novamente, nos deparamos com a dimensão teleológica e futurista, além de um distanciamento do passado como provedor de lições para o presente. Efetiva-se uma perspectiva modernista sobre o tempo.

Destarte, há uma frase bastante significativa nas linhas finais do artigo de Catarin e que toma por base o texto já citado de Hobsbawm: "a inovação beneficia-se da história para elaboração do processo de significados e também da estruturação da forma do

\footnotetext{
${ }^{18}<$ http://www.historianet.com.br/conteudo/default.aspx?codigo=950>.
} 
futuro". Hartog (2013) nos chama atenção que esse tipo de história, cujo futuro explica as histórias passadas, adquiriu progressivamente a roupagem de ciência e elegeu como protagonistas a Nação, o Povo, a República, o Proletariado ou a Sociedade. O tempo se organizou sob um poderoso telos que aprisionou a história em uma marcha rumo ao progresso. Numa rápida navegação pelo site, pode ser constatado que grande parte dos artigos do Historianet são dedicados a esses temas. A ideia de um prognóstico racional é um aspecto marcante nessa perspectiva, um momento de ação política consciente, nos adverte Koselleck (2006); um tempo que se direciona a partir de um ponto de partida do presente em direção ao futuro.

Vamos ao terceiro exemplo, extraído do site Brasil Escola.

A História é a ciência que estuda as ações de homens e mulheres no tempo e no espaço. Criada na tradição ocidental entre os gregos, a História conheceu diferentes formas de definição ao longo dos séculos. De um amontoado de narrativas difusas, o processo de pesquisa e investigação historiográfica passou a ser realizado através de métodos mais bem definidos, garantindo um caráter científico a essa área do conhecimento humano. (...) com o passar do tempo, novos objetos de estudo foram sendo incorporados ao estudo da história, ampliando e muito a área de atuação do historiador. (PINTO, 2016 - Grifos dos autores)

De partida, o texto evoca a clássica definição de história apresentada por Marc Bloch (2001), feita na obra A apologia da história ou o ofício do historiador, embora não mencione a texto. Tal colocação é feita atualizando, a partir de uma relação de gênero, a história dos "homens e mulheres", distinção ainda não dimensionada na obra de Bloch, do começo do século XX. A perspectiva de história apresentada pelo Brasil Escola é bastante distinta das demais. Não há uma organização clássica de assuntos e esses são apresentados a partir de uma clara conexão com o presente. Vemos aqui uma crítica à história enquanto acumulação, ao afirmar a passagem da história de "um amontoado de narrativas difusas" para uma dimensão mais científica a partir de novos métodos. 
No artigo “História Geral”, de Tales Pinto, é feita uma reflexão sobre as divisões da história e suas bases europeias, o que demonstra a compreensão sobre as próprias escolhas realizadas pelo site; nesse sentido, afirma que:

Dentro do que é considerado como História, há ainda outras divisões, e se as seguimos no Brasil, isso se deve ao fato de termos como um dos componentes de nossa formação social os europeus. As divisões da História são: Idade Antiga, ou Antiguidade; Idade Média; Idade Moderna; e Idade Contemporânea. (Pinto, 2017)

Percebemos, aqui, uma consistência no próprio diálogo com a sistematização do saber histórico, o que é um aspecto relevante para o professor que pretende lidar com seus conteúdos em sala de aula. Por outro lado, constatamos que, mesmo apresentando outras abordagens sobre a história que se pautam por uma reflexão mais flexível de temas e conteúdos que não obedecem a uma cronologia convencional, os organizadores não conseguem romper totalmente com tal modelo:

Buscando acompanhar essa forma de divisão da História da humanidade (e algumas outras), o site Brasil Escola criou um espaço dedicado à História Geral, onde é oferecido a estudantes e demais leitores textos que possibilitam o conhecimento dessa disciplina do conhecimento humano (PINTO, 2017)

Em parte, isso pode ser explicado pela força dessa estrutura curricular arraigada no ensino de história do Brasil. Como destacam Flávia Caimi e Helenice Rocha (2014, p. 130) “Essa organização curricular seriada perdurou de forma hegemônica até meados da década de 1980, ainda que tenha coexistido ao longo da década de 1990 com as propostas de história temática e de história integrada". Tal elemento reforça o fato de coexistirem nas páginas diferentes estruturas curriculares baseadas em distintos regimes de historicidade.

No artigo “Afinal, para que serve a História”, de autoria de Rainer de Sousa, temos uma abordagem direta sobre a problemática do tempo e da narrativa histórica. Após fazer uma rápida apresentação sobre os tipos de razão histórica que embalaram a produção do conhecimento, conclui: 
Sabemos que muitos por aí aprenderam que a História é importante para que não cometamos os mesmos erros do passado (...) Em outras palavras, essa ideia sugere que a análise e a crítica do passado determinam o alcance de um futuro livre das mazelas que um dia nos afligiu. (SOUSA, 2016)

O autor nos coloca diante das duas prerrogativas de história que discutimos até aqui: a mestra da vida, provedora de lições e a História como telos e aposta no futuro. Embora, as duas dimensões quase se equivalham em seu texto, ele realiza uma contundente crítica sobre ambas: "de fato, ao observar esse tipo de uso para o passado, somos tentados a romantizar a História como ferramenta indispensável ao progresso" (idem). Faz isso ao mencionar os graves conflitos bélicos dos séculos XX, indícios de que a humanidade não aprendeu com o passado, e vai além:

Temos a chance de intuir que a História não tem essa missão salvadora de alertar ao homem sobre os erros que ele não pode cometer novamente. (...) Sendo assim, a noção de progresso atribuída à História deve ser abandonada em favor de uma investigação dos valores, das relações sociais, conflitos e outros vestígios que nos mostram a transitoriedade e a mutação dos contextos em que os fatos históricos são consumados. (SOUSA, 2016)

$\mathrm{Na}$ breve passagem, assistimos à dissolução dos dois regimes de historicidades. A própria Escola dos Annales se organiza sob uma profunda crítica aos modelos tradicionais de história e à própria ideia de futuro como progresso. Não esqueçamos a morte de seu fundador fuzilado ao final da Segunda Guerra Mundial. Nesse sentido, Hartog destaca que a história do século XX precisou aprender para além da morte e da decadência dos modelos que por séculos a haviam embalado. "Precisou propor um modo de relação entre o passado e o presente" (HARTOG, 2013, p. 144).

Uma relação que, embora não pretendesse lidar com o passado como uma tábua de salvação da humanidade, não o tornasse totalmente estéril para o presente. Assim, Sousa tenta contrapor a desesperança sobre o futuro "não devemos acreditar que o passado não passa de um jogo caótico controlado por jogadores (no caso, os homens) que não sabem definir suas próprias regras" para pensá-lo como "um jogo que tem 
feições múltiplas". Sua preocupação remete, como Hartog destaca, aos primeiros Annales:

\begin{abstract}
A Insistência dos primeiros Annales de Marc Bloch e Lucien Febvre sobre a essencial preocupação do presente assumia também seu sentido em relação esse contexto intelectual. Mais tarde eles colocarão o trabalho do historiador sob o signo de um duplo movimento: do passado para o presente e do presente para o passado. Nisso reside a justificativa da história. (HARTOG, 2013, p. 145)
\end{abstract}

Os textos dos Brasil Escola são em sua maioria escritos por mestres, o que demonstra uma abordagem articulada com o debate acadêmico mais atual. A influência da Escola dos Annales na organização e na apresentação de temas e objetos é inconteste, a exemplo de artigos que discutem a "história do perfume", a "história do comércio", "a situação da mulher da Idade Média", dentre outros. Há também a preocupação com a reflexão de questões teórico-metodológicas da história, como em artigos que discutem concepções e abordagens historiográficas, como "A Escolas dos Annales e o Marxismo", “Importância da Micro História italiana”, para citar alguns.

De forma geral, o site é um bom exemplo do tipo de organização curricular da história no Brasil a partir dos anos de 1990. Segundo Caimi (2009), naquela década houve a predominância da influência da Escola dos Annales tanto no espaço acadêmico, como posteriormente, na estruturação de conteúdos voltados para o ensino de história, ou seja, a substituição da narrativa de eventos por uma história problema. Como resultado para o ensino, essa perspectiva trouxe, segundo a autora, algumas características importantes, tais como: a articulação do conteúdo histórico como a prática social do aluno; uso de diferentes linguagens, ênfase na relação entre o passado e o presente do aluno; relação entre permanências e rupturas; discussão sobre conceitos históricos, introdução aos elementos da pesquisa história na escola; adoção de uma temporalidade plural, em lugar da linear (CAIMI, 2009, p. 10).

Como foi destacado anteriormente, há uma bricolagem de temporalidades distintas que informam essa produção, concedendo-lhe uma dimensão plural. No mesmo site, podemos acessar outras definições bastante peculiares sobre a história, assim, são postos à prova os lugares de indeterminação presente no texto, as frinchas das quais os 
leitores irão se apropriar e significar os elementos de configuração presentes nas narrativas dos sites. A tessitura dessa história experimenta os limites e desafios cotidianos da aceitação ou da rejeição de seus argumentos.

\section{Considerações finais}

Graças aos "estratos do tempo" podemos reunir em um mesmo conceito a contemporaneidade do não contemporâneo, um dos fenômenos mais reveladores. (KOSELLECK, 2014, p. 9)

Segundo Koselleck, pensar o tempo é considerar diferentes estratos que se sobrepõem a partir de durações diferentes e que se intercruzam entre a repetição, mudança e simultaneidade. Desta maneira, há sempre um fator de repetição em qualquer tempo, estratos que estão contidos em ações singulares. Sem "esse tipo de diferenciação nenhuma história pode ser reconhecida ou representada" (KOSELLECK, 2014, p. 13). Assim, a repetibilidade é um elemento fundamental para a própria construção de sentidos para o sujeito no tempo, uma vez que, "cada constituição, instituições e organização no âmbito político, social ou econômico depende de um mínimo de repetição, sem a qual elas não seriam capazes de se adaptar nem de se renovar" (KOSELLECK, 2014, p. 13-14).

Ao analisarmos os sites de ensino de história, pudemos perceber como eles operam exatamente com o cruzamento de vários estratos temporais representados por regimes de historicidades distintos. Isso significa que não podemos definir essa produção histórica apenas por uma linha explicativa e, embora em boa parte dos sites ainda se efetivem práticas historiográficas tradicionais, como demonstramos no texto, há um elemento de singularidade nesse processo. Os conteúdos podem ser consumidos numa apropriação horizontal pelos usuários que os acessam de acordo com as demandas que também são do contexto social e educacional em que vivem. Ao mesmo tempo, podem se apropriar de diferentes modelos que circulam nesse universo. 
Essas páginas não estão alheias ao debate realizado no universo acadêmico, uma vez que a maioria de seus autores têm como formação-base a história. Isso nos dá indício de como o processo de formação do profissional no país também é diverso, não apenas em termos do debate sobre concepções histórico-historiográficas, mas também, sobre formas de compreensão do passado que extrapolam a mera localização de um conteúdo vinculado a qualquer concepção de história. Referimo-nos às maneiras como o tempo é apropriado por esses autores, que por sua vez, convivem ainda com outros espaços de operação do conhecimento histórico como escolas, meios de comunicação, políticas da memória e as demandas advindas do universo virtual.

Embora os autores dos sites e seus leitores sejam tipos de produtores distintos, partilham de processos diretamente ligados ao contexto social que dividem. Há ainda uma clara intenção de formação de um público para as páginas, uma vez que muitos apontam a quem se destina a produção:

Uma das grandes novidades do site é o ESPAÇO DO PROFESSOR, uma área especial, destinada aos docentes de História, com o intuito de agregar valor na vida dos profissionais de ensino, levando conteúdo direcionado e exclusivo. Historianet: <http://www.historianet.com.br/conteudo/default.aspx?codigo=1174>,10/ 09/2016)

Criado para preencher uma lacuna no ensino de História na Web, este portal aborda desde os conteúdos de ensino fundamental até os assuntos mais avançados sobre História. Possui ainda seções com informações históricas importantes, datas comemorativas, curiosidades, efemérides, atualidades, vídeos, personalidades, jogos on-line, exercícios resolvidos e muito mais. (SoHistória: <http://www.grupovirtuous.com.br/>, 10/09/2016)

Tais questões colocam em evidência problemas bastante pertinentes ao ensino de história no tempo presente, como também os lugares de produção histórica. Se por um lado, avançamos em profícuas discussões sobre a relação entre a escrita acadêmica e escrita didática da história, trazendo à tona uma necessidade crescente de diálogo entre ambas as dimensões, por outro, percebemos uma clara disputa de narrativas ensejadas fora das escolas de formação. 
Falamos de diferentes enquadramentos temporais que transitam no universo virtual e que se tornam, cada vez mais, ferramentas poderosas no processo de formação da consciência histórica contemporânea fora da escola. Nossa tarefa diz respeito à compreensão daquilo que Rüsen denomina de formação histórica, ou seja, "todos os processos de aprendizagem em que história é o assunto e que não se destinam, em primeiro lugar, à obtenção de competência profissional” (RÜSEN, 2001, p. 48).

Esta reflexão pode nos indicar que estamos lidando com experiências temporais distintas que ocorrem simultaneamente, o que diz respeito à própria historicidade da produção do pensamento histórico em nossa sociedade hoje. Isso significa considerar diversos fluxos de sentido e significação em nossa cultura histórica. Para nos remetermos novamente ao conceito de regime de historicidade proposto por Hartog (2013), podemos dizer que nossa sociedade tem operado em ritmos diferentes na construção de narrativas históricas. Portanto, essas narrativas advindas do universo virtual nos possibilitam compreender processos de construção, apropriação e distribuição de conteúdos realizados por seus usuários divididos em vários estratos que se cruzam e fazem parte do nosso próprio processo de formação histórica.

\section{Referências}

ABUD, Katia. O livro didático e a popularização do saber histórico. In: SILVA, Marcos.

Repensado a história. Rio de Janeiro: Editora Zero, 1986.

BITENCOURT, Circe. O saber histórico na sala de aula. 2. ed. São Paulo: Contexto, 1998.

BLOCH, Marc. A Apologia da História ou o oficio do historiador. Rio de Janeiro, Jorge Zhar Editor. 2001.

BORGES, Jorge Luis. A Biblioteca de Babel. Obras Completas. São Paulo, Ed. Globo 1999.

BRASIL deve fechar 2014 como $4^{\circ}$ país com mais acesso à internet, diz consultoria. In:

BBC: Português Noticias. 2014. Disponível em: 
<http://www.bbc.com/portuguese/noticias/2014/11/141124_brasil_internet_pai>. Acesso em 15/07/2016.

CAIMI, Flávia Eloisa. História convencional, integrada, temática: uma opção necessária ou um falso debate? In: SIMPÓSIO NACIONAL DE HISTÓRIA, XXV, Fortaleza, 2009. Anais. da ANPUH.

CAIMI, Flávia Eloisa; ROCHA, Helenice. A(s) história(s) contada(s) no livro didático hoje: entre o nacional e o mundial. Revista Brasileira de História, São Paulo, v. 34, n. 68, p. 125$147,2014$.

CANCLINI, Néstor Garcia. Leitores, Espectadores e Internautas. São Paulo, Ed. Iluminuras. 2008.

CERTEAU, Michel. A escrita da história. Rio de Janeiro: Forense Universitária, 2002.

FONSECA, Selva Guimarães. Caminhos da história ensinada. Campinas: Papirus, 1993.

GRUPO VIRTUOS. Disponível em: <http://www.grupovirtuous.com.br/>. Acesso em $17 / 05 / 2017$.

HARTOG, François. Regimes de historicidade: presentíssimo e experiências do tempo. Rio de Janeiro: Autêntica, 2013.

HOBSBAWM, Eric. Sobre história. São Paulo: Cia das Letras, 2002.

HISTORIANET.COM. Disponível em: <http://www.historianet.com.br/home/>. Acesso em 2016.

KOSELLECK, Reinhart. Futuro passado: contribuição à semântica dos tempos históricos. Rio de Janeiro: Ed. PUC Rio, 2006.

HAY más de 330 millones de internautas en Latinoamérica. In: LATINLINK [Blog da Internet]. 2016. Disponível em: <http://latinlink.usmediaconsulting.com/2014/08/hay-masde-330-millones-de-internautas-en-latinoamerica/?lang=es>. Acesso 15/07/2016.

MACHADO, Geraldo Magela. História. In: Infoescola: Ciências. 2016. Disponível: <http://www.infoescola.com/ciencias/historia/>. Acesso em: 19/09/2016.

MELO, Francisco Egberto. Currículo e ensino de história local no mundo globalizado. Recife: Gráfica e Editora Liceu, 2014.

MENESES, Sônia. Os historiadores e os "fazedores de história": lugares e fazeres na produção da memória e do conhecimento histórico contemporâneo a partir da influência midiática. OPSIS, v. 7, n. 9, jul./dez., 2007. 
NADAI, Elza; BITENCOURT, Circe. O Ensino de história e a criação do fato. Rio de Janeiro: Contexto, 1988.

OLIVEIRA, Nucia Alexandra Silva de. História e internet: conexões possíveis. Revista Tempo e Argumento, Florianópolis, v. 6, n. 12, p. 23-53, maio/ago. 2014.

PINTO, Tales. História. In: Infoescola: Brasil Escola, 2016. Disponível em: <http://brasilescola.uol.com.br/historia/>. Acesso em: 19/09/2016.

RÜSEN, Jörn. Razão Histórica. Brasília, Ed. UNB. 2001

SANTOS, Carlos Aparecido. O Teatro na época da Ditadura. In: Historianet, 2015. Disponível em: <http://historianet.com.br/conteudo/default.aspx?codigo=716>. Acesso em 29/10/2015.

SILVA, Marcos. Repensado a história. Rio de Janeiro: Editora Zero, 1986.

SOUSA, RAINER. Afinal para que serve a história? In: Infoescola: Brasil Escola, 2016. Disponível em: <http://brasilescola.uol.com.br/historia/afinal-para-que-servehistoria.htm.> Acesso em: 29/09/2016. 